Sharif University of Technology
Scientia Iranica
Transactions A: Civil Engineering
IRAENTIA
IRttp://scientiairanica.sharif.edu

\title{
The experimental assessment of the effect of polypropylene fibers on the improvement of nano-silica concrete behavior
}

\author{
S. Piroti ${ }^{\mathrm{a}}$, M. Najarchi ${ }^{\mathrm{a}, *}$, E. Hezavehi ${ }^{\mathrm{b}}$, M.M. Najafizadeh ${ }^{\mathrm{c}}$, and \\ S.M. Mirhosseini ${ }^{a}$
}

a. Department of Civil Engineering, Arak Branch, Islamic Azad University, Arak, Iran.

b. Department of Textile Engineering, Arak Branch, Islamic Azad University, Arak, Iran.

c. Department of Mechanical Engineering, Arak Branch, Islamic Azad University, Arak, Iran.

Received 26 February 2018; received in revised form 12 March 2018; accepted 29 May 2018

\section{KEYWORDS}

Concrete;

Water-cement ratio;

Nano-silica;

Polypropylene fiber;

Mechanical properties.

\begin{abstract}
In this study, the effect of water-cement ratio on the mechanical properties (compressive, abrasion, tensile, flexural strength, and permeability) of nano-silica concrete reinforced with polypropylene fibers is evaluated. The specimens contain $4 \%$ of nano-silica, $0.30,0.35,0.40,0.45$, and 0.50 of water-cement ratios, and $0,0.10,0.15,0.25$, and 0.35 percent volumes of polypropylene fibers. Other design features remain fixed in all concrete samples. The results of the experiments showed that with decreasing the ratio of water to cement from 0.50 to 0.30 , all the mechanical properties of the concrete were improved. In addition, the test results showed a significant increase in mechanical properties improvement of concrete by using polypropylene fibers. Tensile strength, flexural strength, and abrasion resistance of concrete increased up to $22 \%, 40 \%$, and $27 \%$, respectively, for the 28-day age specimens. In addition, a considerable reduction of hydraulic conductivity coefficient to $51 \%$ indicates high durability of these types of concrete. Compressive strength showed increment rates of $22 \%, 15 \%$, and $14 \%$ for 7 -, 28-, and 90 -day age specimens, respectively.

(C) 2020 Sharif University of Technology. All rights reserved.
\end{abstract}

\section{Introduction}

In recent years, the durability and service life of cementitious materials have been playing an important role in their operation as construction and pavement materials [1]. Nanotechnology has attracted considerable scientific interest due to the new potential uses of particles on a nanometer scale. Nano-technology

\footnotetext{
*. Corresponding author.

E-mail addresses: s.piroti@iau-mahabad.ac.ir (S. Piroti);

mohsen.najarchii@gmail.com (M. Najarchi);

e-hezave@iau-arak.ac.ir (E. Hezavehi);

m-najafizadeh@iau-arak.ac.ir (M.M. Najafizadeh);

m-mirhoseini@iau-arak.ac.ir (S.M. Mirhosseini)
}

doi: $10.24200 /$ sci.2018.50514.1735 encompasses the techniques of manipulation of the structure on the nanometer scale to develop a new generation of tailored, multifunctional cementitious composites with superior mechanical performance and durability, potentially having a range of novel properties such as low electrical resistivity, self-sensing capabilities, self-cleaning, self-healing, high ductility, and self-control of cracks. Concrete can be nanoengineered by the incorporation of nano-sized building blocks or objects (e.g., nano-articles and nano-tubes) to control material behavior and add novel properties, or by the grafting of molecules onto cement particles, cement phases, aggregates, and additives (including nano-sized additives) to provide surface functionality, which can be adjusted to promote specific interfacial interactions [2]. The nano-scale size of particles 
can result in dramatically improved properties from conventional grain-size materials of the same chemical composition. Thus, industries may be able to reengineer many existing products and design new and novel products that function at unprecedented levels. When ultra-fine particles are incorporated into Portland-cement paste, mortar or concrete, materials with characteristics different from those of conventional materials are obtained. The performance of these cement-based materials is strongly dependent on nanosized solid particles of Calcium-Silicate-Hydrates (C$\mathrm{S}-\mathrm{H}$ ), or nano-sized porosity at the interfacial transition zone between cement and aggregate particles. Typical properties affected by nano-sized particles or voids include strength, durability, shrinkage, and steelbond [3]. It seems that, in the near future, significant developments will be observed in concrete technology thanks to the introduction of nano- $\mathrm{SiO}_{2}$ with high purity and a finer particle size. Studies have shown that the application of nano- $\mathrm{SiO}_{2}$ into the production of mortar and concrete would lead to improvement in compressive strength, flexural behavior, and abrasion resistance $[4,5]$. Therefore, nano- $\mathrm{SiO}_{2}$ can be applied to the production of High-Performance Concrete (HPC), which has gradually replaced normal strength concrete. The rate of pozzolanic reaction is proportional to the amount of surface available for reaction and owing to the high specific surface of nano particles. They possess high pozzolanic activity and consume Calcium Hydroxide $(\mathrm{CH})$, which arrays in the interfacial transition zone between hardened cement paste and aggregates, and produce Calcium Silicate Hydrates (C-S-H), which enhances the strength of cement paste. Polypropylene fibers have been widely used for the reinforcement of cementitious materials to improve the toughness and energy absorption capability of the matrix [6]. Ozawa and Morimoto [7] carried out permeability tests on high-strength concretes (72 MPa) including $0.15 \%$ volume of polypropylene fibers (PPF). Results showed the residual permeability increasing 12 times after heating the $\mathrm{PPF}$ concrete to $500^{\circ} \mathrm{C}$ compared to the reference concrete. Thus, the improvement of permeability increase reduces the likelihood of explosive spalling. Dehghan et al. [8] focused on experimental evaluation and numerical simulation of a simple practical retrofitting technique employing Fiber Reinforced Concrete (FRC) surface layer. In their research, the simple FRC mix has conventional available fiber, lowfiber content, ordinary mix design, and applicable construction procedure. Effects of FRC mix including fiber type and fiber content and surface layer thickness on in-plane behavior of masonry panels made up of conventional solid clay bricks were evaluated through experimental study in accordance with ASTM E-519 diagonal tension strength of masonry panels. In addition, they investigated the numerical simulation model of this retrofitting technique in ABAQUS software and validated test results of bare and retrofitted panels.

Badv and Omidi [9] found PPF extremely effective in reducing free plastic shrinkage, retarding first crack appearance, and controlling crack development. Research results indicated that the ductility of concrete using fiber greatly increased. Additionally, an overall improvement in the application of fiber is an increase in tensile, flexural, and shear strength. Concrete cracking can be delayed and controlled with the application of fibers in concrete. Compressive strength of concrete is increased by adding some kind of fibers to concrete mixtures [10,11]. Another advantage of adding fibers to concrete mixture is the improvement in cavitation resistance, ductility, toughness, and resistance to abrasion and erosion [12]. In recent years, many studies have been conducted on the mechanical characteristics of reinforced fiber concrete. Such concrete is used in retrofitting and repairing the covering of concrete structure tunnels, carpentries stabilizing, asphalts, etc. According to the results of research studies, the increase of formability and bending strength are the extra advantages of adding fiber to concrete. Two kinds of fiber used very often in the concrete include steel fiber and polypropylene fiber $[13,14]$. Shariati et al. [15] performed an experimental study to investigate the behavior of angle shear connectors embedded in High-Strength Concrete (HSC) slab. Eight push-out specimens were tested to cover various geometries of angle shear connector. On top of the experimental study, the accuracy of the available equations in estimating the load capacities of angle connectors was also evaluated for the angles embedded in HSC. Their results showed inadequate ductility behavior for the angle shear connectors embedded in HSC. Nonetheless, the angle connectors exhibited good behavior in the case of strength degradation under cyclic loading.

Nanotechnology is an emerging avenue of research with a potential impact on every domain of science and technology [16]. There are a number of definitions for nanotechnology given by many researchers. All these advantages are pertinent to the kind of fiber and its concentration in the mixture; its high melting point $\left(170^{\circ} \mathrm{C}\right)$ and its chemical neutrality make it strong acidic and alkali resistant. Polypropylene fibers have hydrophobic levels, which protect them against wetting with cement paste. The hydrophobic nature of polypropylene has no effect on the amount of water needed for concrete [17-19]. Concrete is the most widely used construction material because of the several well-known advantages it offers such as low cost, general availability, and wide applicability. However, concrete is a quasi-brittle material, and its brittleness increases with its strength. Relatively low tensile strength and poor resistance to crack opening and propagation are the main disadvantages of conven- 
tional concrete [20,21]. Development of modern civil engineering construction has generated an essential demand for new types of concretes, which should possess improved qualities such as high-strength, toughness, and durability [22]. Currently, fiber plays a very important and rapidly growing role in modern concrete technology. Harnessing fiber as concrete reinforcement allows enhancing its mechanical properties and obtaining significant economic benefits. Fiber quickly becomes an important element of sustainable development of the construction industry [23]. Examples of new types of concrete include HSC, HPC, and highperformance fiber-reinforced concrete. The properties of such concretes show a substantial improvement over those of conventional concrete [24,25]. However, HSC is more brittle than normal-strength concrete, and this limits the utilization of HSC. Additionally, it is well understood that the use of supplementary cementitious materials such as silica fume, ground granulated blastfurnace slag, and fly ash as part of binders is required for the production of high-strength concretes [26,27].

Considering the effect of water-cement ratio and PPF on five mechanical characteristics of concrete (including compressive, abrasion, tensile, flexural strengths, and hydraulic conductivity coefficient) and studying the behavior of concrete in a wider range are the objectives of this research in order to obtain their optimum percentages. Finding this optimum percentage for the application of fiber-reinforced concrete in different hydraulic and building structures is the main novelty of the present manuscript.

\section{Material properties and experimental setup}

\subsection{Materials}

In preparation of samples of nano-silica concrete mixture, the following components were considered:

- Compressive strength of the 28-day specimen is 45 $\mathrm{MPa}$;

- The cement used in these experiments is Portland cement Type I $(52.5 \mathrm{~N})$;

- The water-cement ratios are 0.30, 0.35, 0.40, 0.45, and 0.50

- The maximum diameter of aggregates is $10 \mathrm{~mm}$;

- The amount of fixed nano-silica and 4\% consumption cement are replaced;

- Type of fibers is polypropylene with $19 \mathrm{~mm}$ length and $0.01 \mathrm{~mm}$ diameter and considered 0, 0.10, 0.15, 0.25 , and 0.35 percent volumes;

- Glenium SKY 592 was used as superplasticizer;

- The aggregates (gravel and sand) were of ballast type;
Table 1. Chemical compositions of the used nano-silica [28].

\begin{tabular}{cc}
\hline $\begin{array}{c}\text { Chemical } \\
\text { component }\end{array}$ & $\begin{array}{c}\text { Nano-silica } \\
\text { content (\%) }\end{array}$ \\
\hline $\mathrm{SiO}_{2}$ & 96 \\
$\mathrm{AL}_{2} \mathrm{O}_{3}$ & 0.40 \\
$\mathrm{Fe}_{2} \mathrm{O}_{3}$ & 0.35 \\
$\mathrm{CaO}$ & 0.20 \\
$\mathrm{MgO}$ & 0.25 \\
$\mathrm{Na}_{2} \mathrm{O}$ & 2.25 \\
$\mathrm{~K}_{2} \mathrm{O}$ & 0.27 \\
$\mathrm{SO}_{3}$ & 0.28 \\
\hline
\end{tabular}

Table 2. Properties of polypropylene fibers (PPF) [28].

\begin{tabular}{cc}
\hline Specific gravity $\left(\mathrm{kg} / \mathrm{m}^{3}\right)$ & 910 \\
Tensile strength $(\mathrm{MPa})$ & 300 \\
Elastic modulus $(\mathrm{MPa})$ & 3500 \\
Fiber length $(\mathrm{mm})$ & 19 \\
Fiber diameter $(\mathrm{mm})$ & 0.01 \\
Aspect ratio $(\mathrm{l} / \mathrm{d})$ & 1900 \\
Melting point $\left({ }^{\circ} \mathrm{C}\right)$ & 170 \\
\hline
\end{tabular}

- The slump test range of specimens was 50 to $100 \mathrm{~mm}$.

The results of chemical analysis of nano-silica and the chemical and physical characteristics of polypropylene fibers are shown in Tables 1 and 2, respectively. PPFs are resistant against chemical materials such as acids, alkalis, and chlorides and have low electrical and thermal conductivity. Figures 1 and 2 show the use of nano-silica and polypropylene fibers in the construction of test samples, respectively.

The grading of aggregates and mixture design of nano-silica concrete containing PPFs were in accordance to ASTM C136 [29] and ACI-211 [30] standards, respectively. The fiber concrete mixture design is shown in Table 3, and every mixture design was conducted with a weighting method, and the results are shown in Table 4.

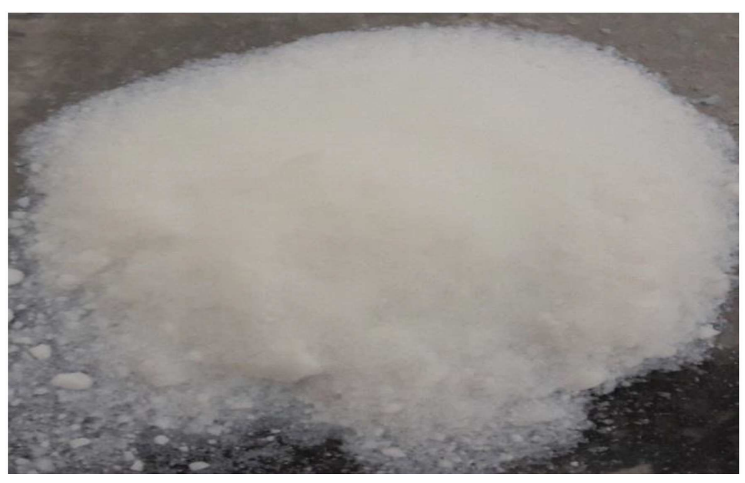

Figure 1. Nano-silica used for reinforcing concrete. 


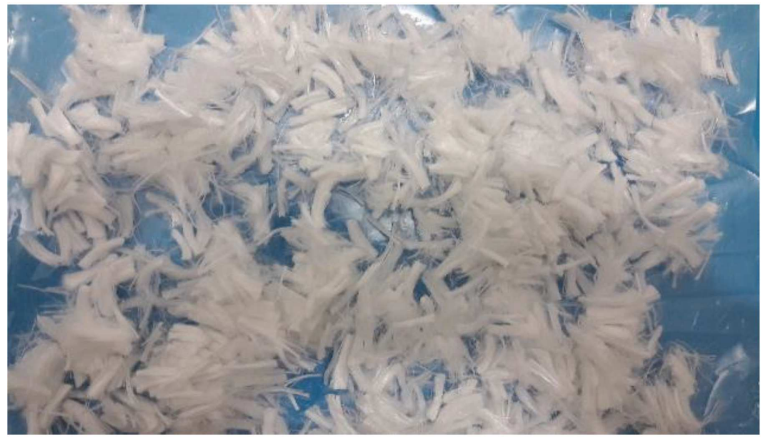

Figure 2. Polypropylene fibers used for reinforcing concrete.

\subsection{Testing methods}

The following tests have been done on concrete specimens in this research:

- Compressive strength test on $150 \times 150 \times 150 \mathrm{~mm}$ cubic specimens at the ages of 7,28 , and 90 days by special jacks according to BS 1881 part 116 [31] standard. The following equation was used for compressive strength calculation:

$$
\text { Compressive Strength }=P / A \text {, }
$$

where $P$ is the applied load at fracture, and $A$ is the cross-sectional area of cubic samples;

- Abrasion resistance test on $150 \times 150 \times 150 \mathrm{~mm}$ cubic specimens at the age of 28 days by water sandblasting method according to ASTM C418 [32] standard. The following equation was used for abrasion depth calculation:

$$
h_{e}=V / A \text {, }
$$

where $h_{e}$ is the abrasion depth, $V$ is the volume of holes, and $A$ is the area of the triturated surface;
- Hydraulic conductivity coefficient measurement test on $150 \times 300 \mathrm{~mm}$ cylindrical specimens at the age of 28 days by the penetration depth method according to ISO 1920-5 [33] standard. The following equations were used to calculate the hydraulic conductivity coefficient and porosity of specimens:

$$
K_{p}=h_{p}^{2} V / 2 T h,
$$

where $K_{p}$ is the permeability coefficient of concrete, $\mathrm{m} / \mathrm{s} ; h_{p}$ is the water permeability depth, $\mathrm{m} ; \quad T$ is the water permeability time, sec; $h$ is the height arising from pressure, $\mathrm{m}$; and $V$ is the concrete porosity. The formula for porosity is given as follows:

$$
V=\{(w / c) \times(100-36.15 \times \alpha) /(w+100 / g)\},
$$

where $w / c$ is the water-cement ratio; $\alpha$ is the cement hydration degree; $w$ is the gravity water of concrete, $\mathrm{Kg} / \mathrm{m}^{3}$, and $\mathrm{g}$ is the cement specific weight, $\mathrm{gr} / \mathrm{cm}^{3}$;

- Tensile strength test on $150 \times 300 \mathrm{~mm}$ cylindrical specimens at the age of 28 days by indirect splitting method (Brazilian test) according to ASTM C496 [34] standard. The following equation was used for tensile strength calculation:

$$
f_{c t}=\frac{2 P}{\pi L D},
$$

where $P$ is the applied load at fracture moment, and $L$ and $D$ are the length and diameter of the cylinder, respectively;

- Flexural strength test on $100 \times 100 \times 500 \mathrm{~mm}$ prismatic beam specimens at the age of 28 days according to ASTM C1018 [35] standard. The following equation was used for flexural strength calculation:

Table 3. Fiber concrete mixture designs.

\begin{tabular}{cccc}
\hline $\begin{array}{c}\text { Scheme } \\
\text { number }\end{array}$ & $\begin{array}{c}\text { Polypropylene } \\
\text { fiber (\%) }\end{array}$ & $\begin{array}{c}\text { Polypropylene } \\
\text { fiber content }(\mathrm{kg})\end{array}$ & $\begin{array}{c}\text { Superplasticizer } \\
(\%)\end{array}$ \\
\hline 1 & 0.10 & 0.63 & \\
2 & 0.15 & 0.94 & 2.5 \\
3 & 0.25 & 1.57 & \\
4 & 0.35 & 2.21 & \\
\hline
\end{tabular}

Table 4. Concrete mixture design proportions $\left(\mathrm{kg} / \mathrm{m}^{3}\right)$.

\begin{tabular}{cccccc}
\hline W/C & Water & Nano-silica & Cement & Sand & Gravel \\
\hline 0.30 & 150 & 20 & 480 & 800 & 860 \\
0.35 & 175 & 20 & 480 & 800 & 860 \\
0.40 & 200 & 20 & 480 & 800 & 860 \\
0.45 & 225 & 20 & 480 & 800 & 860 \\
0.50 & 250 & 20 & 480 & 800 & 860 \\
\hline
\end{tabular}




$$
f_{r}=\frac{P L}{b d^{2}}
$$

where $P, L, b$, and $d$ are the applied load at fracture moment, the length of specimen, the section's width, and the section's height, respectively.

\section{Results and discussion}

\subsection{Compressive strength test results}

The variation curves of compressive strength of specimens containing fibers at the ages of 7,28 , and 90 days in terms of water-cement ratio and fiber percent for different mixture designs are shown in Figure 3. The highest compressive strength of all specimens pertains to the specimens with a water-cement ratio of 0.30 , and

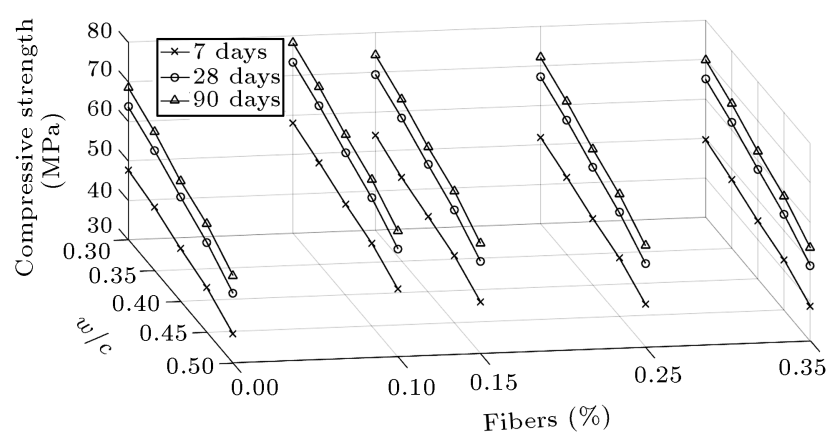

Figure 3. The variation curve of compressive strength of specimens at the ages of 7,28 , and 90 days with respect to water-cement ratio and fiber percent. the lowest compressive strength is for the water-cement ratio of 0.50 samples.

Figure 4 shows that the addition of $0.10 \%$ fibers improves the compressive strength of specimens at the ages of 7,28 , and 90 days by $22 \%, 15 \%$, and $14 \%$, respectively. In addition, $0.15 \%$ addition of fibers to the specimens improves the compressive strength at the mentioned ages by about $13 \%, 9 \%$, and $8 \%$, respectively. Furthermore, the addition of fibers to the specimens improves the compressive strength at the mentioned ages by about $9 \%, 6 \%$, and $5 \%$ for $0.25 \%$ of fibers and $7 \%, 4 \%$, and $3 \%$ for $0.35 \%$ of fibers, respectively.

Using $0.10 \%$ of fibers and $4 \%$ nano-silica increases the compressive strength at the ages of 7,28 , and 90 days. More than $0.10 \%$ utilization of fibers decreases the compressive strength of specimens at any age due to unsuitable distribution of fibers. The constant value of superplasticizer and the increasing fibers content decrease the slump of concrete and affect the reduction of compressive strength of specimens. The porosity of concrete specimens increases by the addition of fibers.

\subsection{Abrasion resistance test results}

Figures 5 and 6 show the chart of abrasion depth of fibrous and non-fibrous specimens in terms of watercement ratio. It can be concluded that the slope of abrasion depth curve dwindles by increasing the watercement ratio from 0.30 to 0.50 ; this can be related to the biphasic (mortar and aggregates) nature of concrete in abrasion. The abrasion resistance of mortar phase

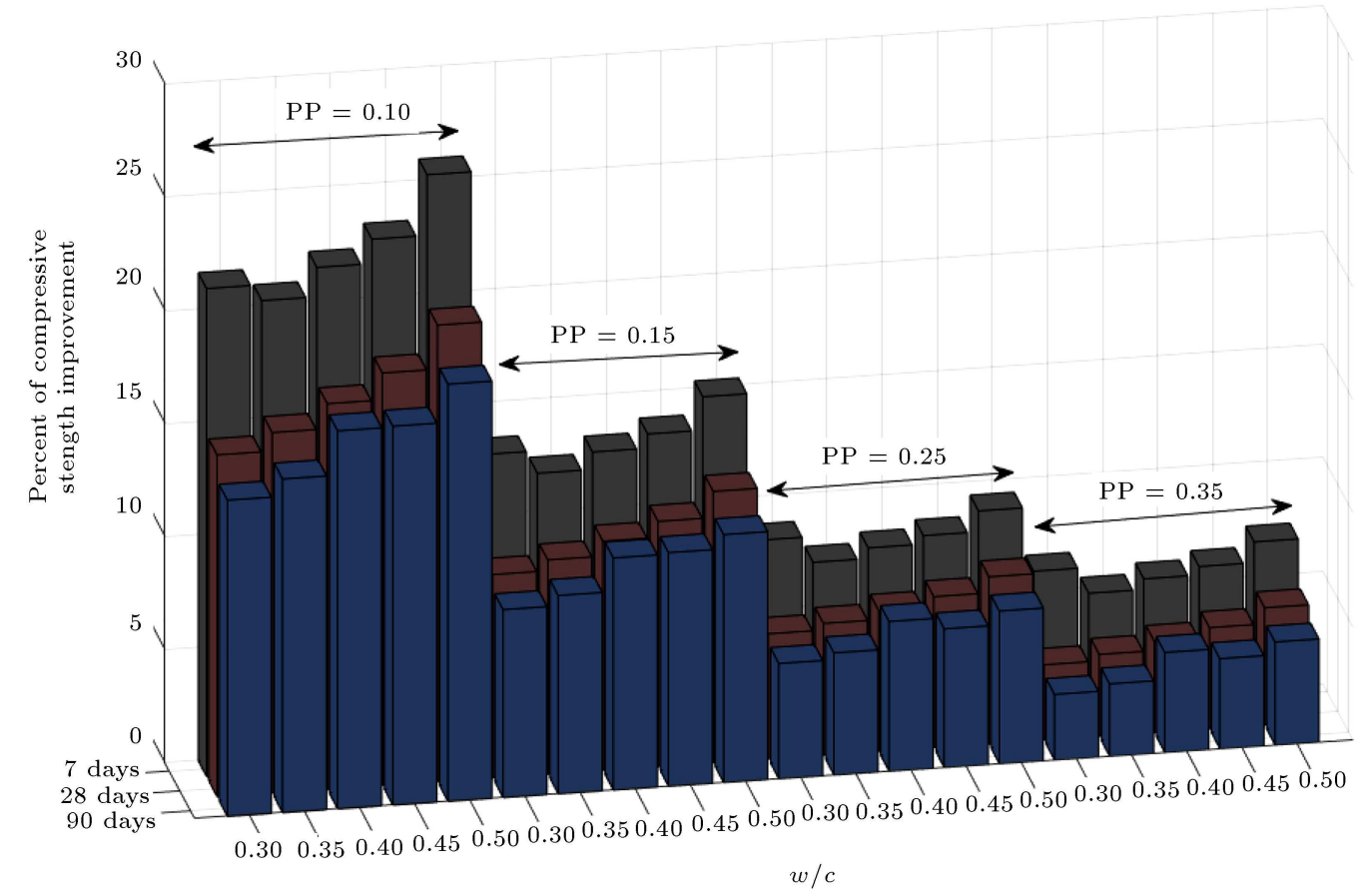

Figure 4. Compressive strength improvement of fibrous specimens with respect to water-cement ratios at the ages of 7 , 28 , and 90 days. 


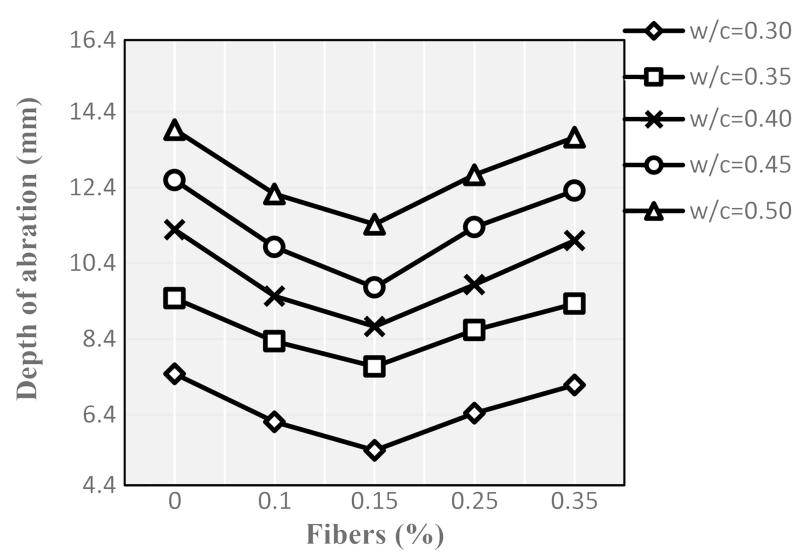

Figure 5. The fluctuation curve of abrasion depth with respect to water-cement ratio and fiber percent.

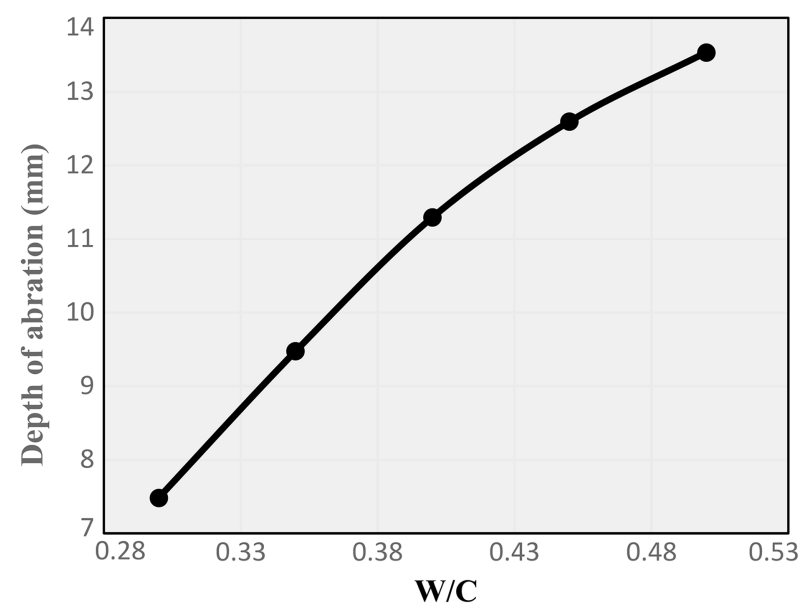

Figure 6. The variation curve of abrasion depth with respect to water-cement ratio.

decreases by increasing the water-cement ratio, and the abrasion resistance of concrete approaches the abrasion resistance of aggregates.

Figure 7 shows the variation of abrasion resistance in terms of 28-day compressive strength of concrete. It can be concluded that the abrasion resistance of concrete increases by increasing compressive strength. In other words, those that increase the compressive strength of concrete can improve the abrasion resistance of concrete, too.

Figure 8 shows that at the water-cement ratios of $0.30,0.10 \%, 0.15 \%, 0.25 \%$, and $0.35 \%$, addition of fibers to the specimens improves their abrasion resistance by $17 \%, 27 \%, 9 \%$, and $6 \%$, respectively. The $\mathrm{PPF}$ prevent the bleeding and transmission of water to concrete's surface, which improves the homogeneity of concrete, uniformity of water-cement ratio at all parts of the specimen, and continuity of hydration. This fiber reduces the permeability of concrete's surface and increases the concrete's age and abrasion resistance that prevents disintegration and lamination of concrete's surface. Using up to $0.15 \%$ of fibers and $4 \%$ nano-

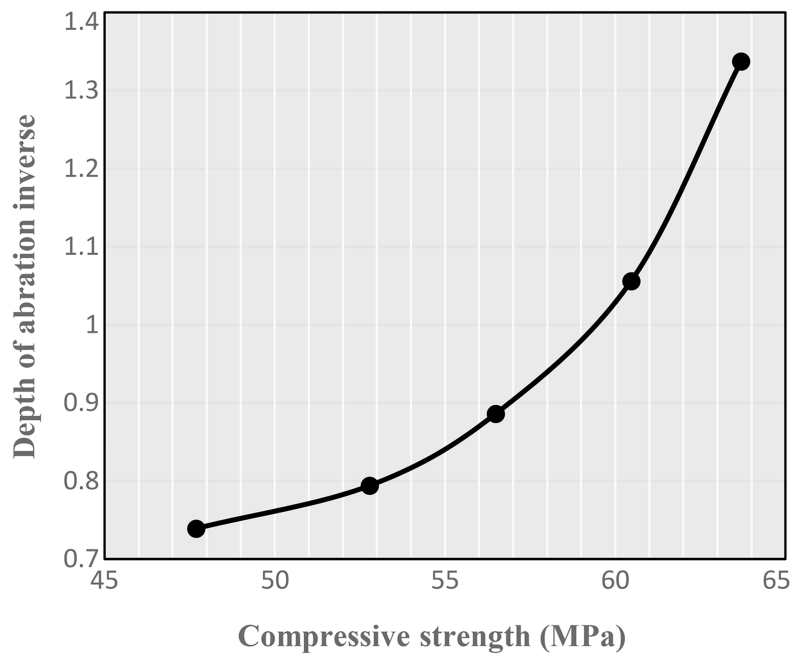

Figure 7. The fluctuation curve of abrasion resistance with respect to compressive strength.

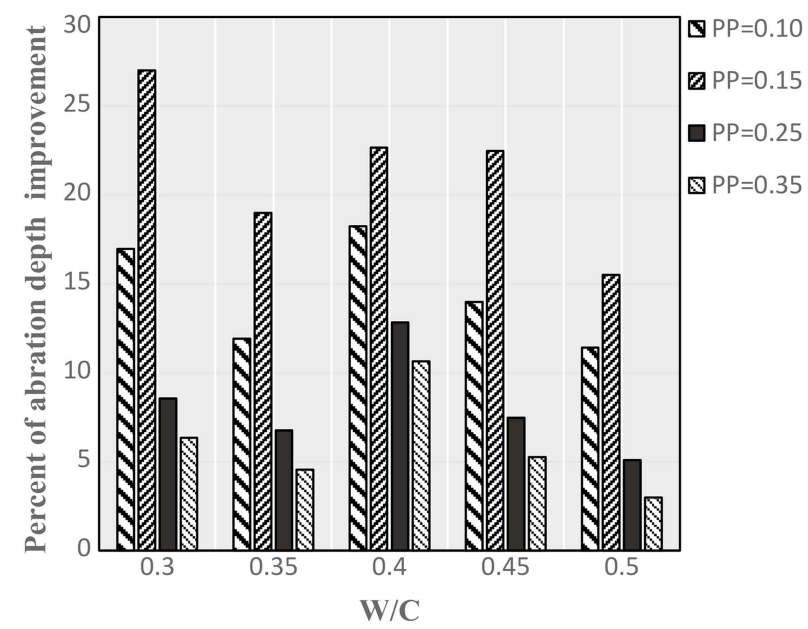

Figure 8. The chart of abrasion depth improvement with respect to water-cement ratio and fiber percent.

silica increases the abrasion resistance of the specimens. Their abrasion resistance decreases by more than $0.15 \%$ addition of fibers due to the porosity increment of the specimens.

\subsection{Hydraulic conductivity coefficient test results}

Figure 9 shows the variation curve of water's penetration depth of fibrous and non-fibrous specimens in terms of different amounts of water-cement ratio. Water's penetration depth increases by increasing the water-cement ratio.

Figure 10 indicates the diagram of changes in hydraulic conductivity coefficient of fibrous and nonfibrous specimens in terms of different amounts of water-cement ratio. Hydraulic conductivity coefficient of concrete increases with an increase in the watercement ratio.

Figure 11 shows that at the water-cement ratios 


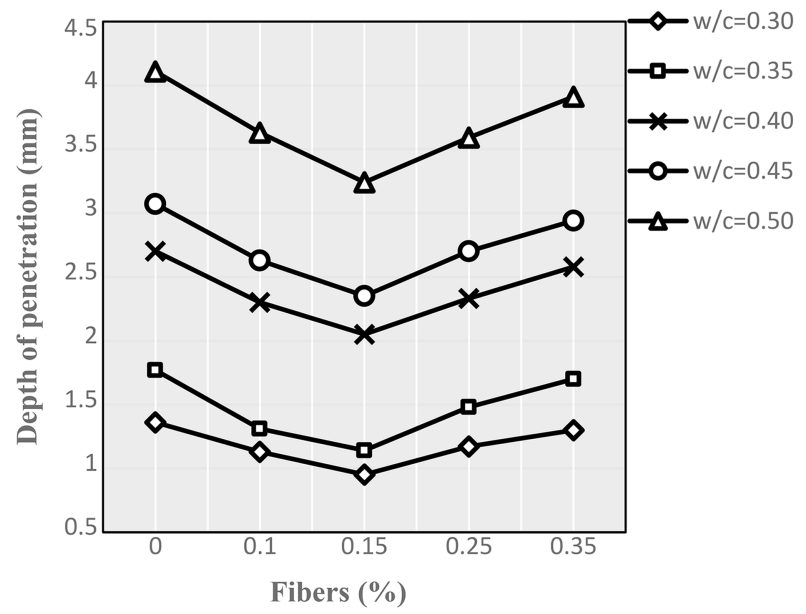

Figure 9. The fluctuation curve of penetration depth with respect to water-cement ratio and fiber percent.

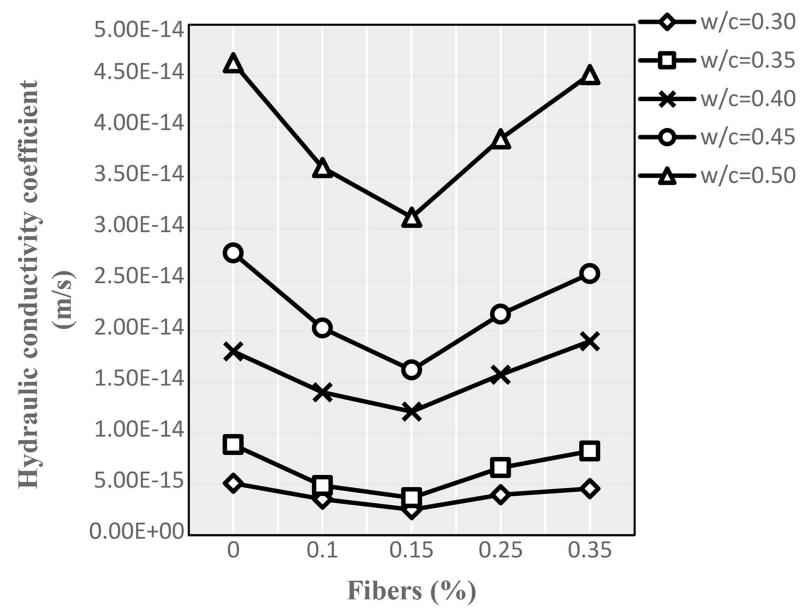

Figure 10. The variation curve of hydraulic conductivity coefficient with respect to water-cement ratio and fiber percent.

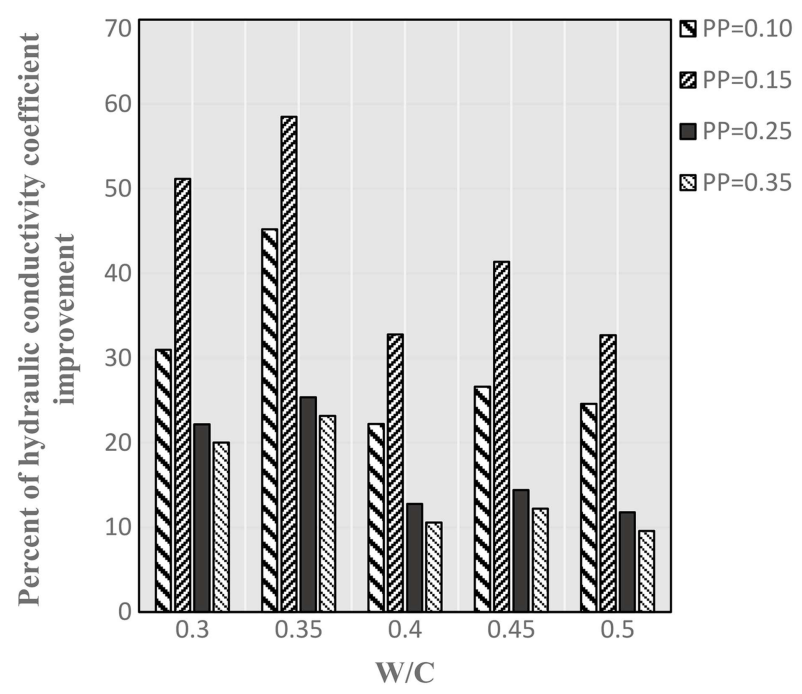

Figure 11. The chart of hydraulic conductivity coefficient improvement with respect to water-cement ratio and fiber percent. of $0.30,0.10 \%, 0.15 \%, 0.25 \%$, and $0.35 \%$, addition of fibers to the specimens improves the penetration depth of water by $17 \%, 30 \%, 22 \%$, and $20 \%$, respectively.

The reduction of penetration depth of water in the presence of fibers results from the placement of fibers between the connection paths of pores that obstruct them; hence, the capillarity that is a resonant factor of permeability will be removed and, therefore, the permeability of specimens will reduce.

Using up to $0.15 \%$ of fibers and $4 \%$ nano-silica decreases the penetration depth of water and permeability of specimens. These factors will increase if more than $0.15 \%$ of fibers are used. This behavior results from the porosity increment of specimens.

\subsection{Tensile strength test results}

Figure 12 shows that $0.10 \%$ addition of fibers places a sensible effect on tensile strength. Higher proportions of fibers increase the tensile strength of the specimens with a lower slope.

Non-fibrous specimens experience a type of disintegration during fracture. The application of fibers resolves this problem completely.

Figure 13 shows that at 0.30 of water-cement ratio, $0.10 \%, 0.15 \%, 0.25 \%$, and $0.35 \%$ additions of fibers to the specimens improve their tensile strength by $17 \%, 20 \%, 22 \%$, and $19 \%$, respectively.

Ordinary concrete has low tensile strength, which is one of its shortcomings. Using fibers will increase the tensile strength and ductility of concrete due to the high tensile strength of fibers.

Using up to $0.25 \%$ of fibers and $4 \%$ nano-silica increases the tensile strength of specimens. It is seen that the tensile strength of the specimens decreases if more than $0.25 \%$ of fibers are used. This behavior is due to the unsuitable distribution of fibers, which is obvious on the apparent surface of those specimens. The fracture line has approximately passed through

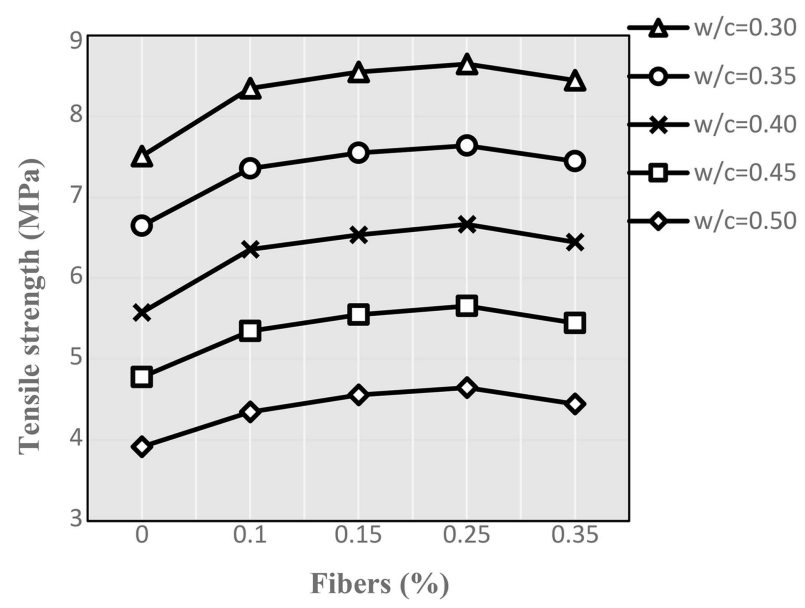

Figure 12. The fluctuation curve of tensile strength with respect to water-cement ratio and fiber percent. 


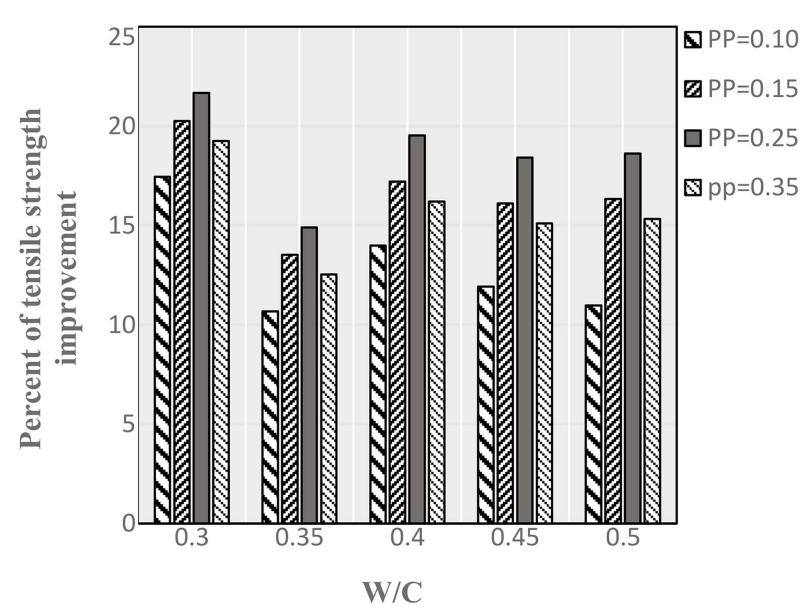

Figure 13. The chart of tensile strength improvement with respect to water-cement ratio and fiber percent.

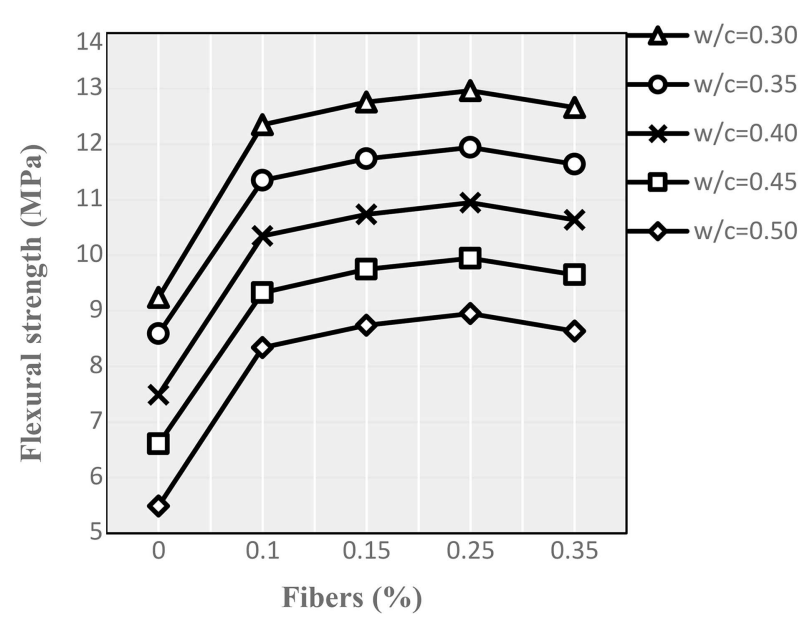

Figure 14. The variation curve of flexural strength with respect to water-cement ratio and fiber percent.

the regions with less fiber density. In other words, using more than $0.25 \%$ of fibers in specimens causes the balling phenomenon, which exterminates the effect of fibers practically.

\subsection{Flexural strength test results}

Figure 14 shows that $0.10 \%$ addition of fibers places a sensible effect on flexural strength. Higher proportions of fibers increase the flexural strength of specimens with a lower slope. In the presence of fibers at specimens, two main statuses between cracks and fibers are observed: vertical and horizontal. If fibers pass through the edges of cracks vertically, the integrity of concrete will be preserved until large deformations due to fibers bridging cracks occur and the flexural strength increases due to cracks sewn by fibers.

Figure 15 shows that at 0.30 of the water-cement ratio, $0.10 \%, 0.15 \%, 0.25 \%$, and $0.35 \%$ additions of fibers to the specimens improve the flexural strength of specimens by $34 \%, 38 \%, 40 \%$, and $36 \%$, respectively.

Using fibers in ordinary concrete as a brittle ma-

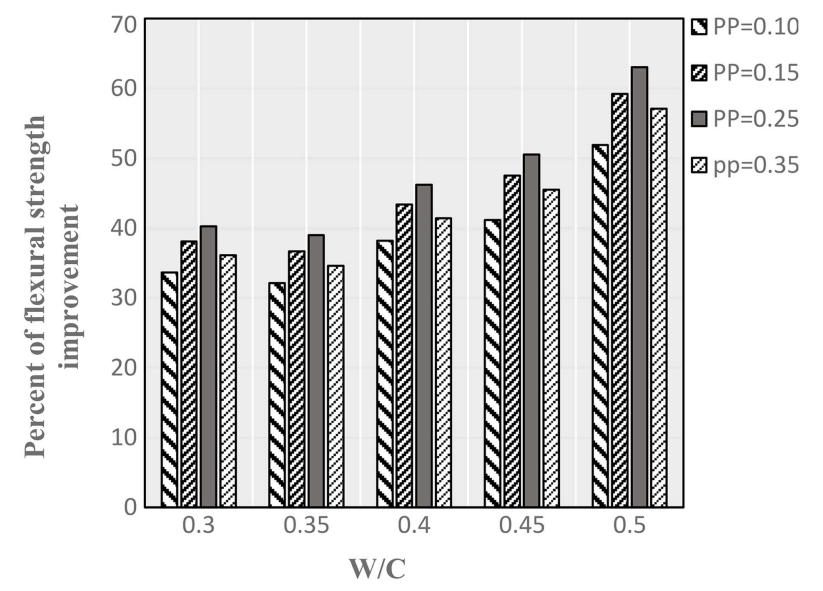

Figure 15. The chart of flexural strength improvement with respect to water-cement ratio and fiber percent.

terial increases the ductility of specimens and improves the flexural strength of concrete.

Using up to $0.25 \%$ of fibers and $4 \%$ nano-silica increases the flexural strength of the specimens. It is achieved that their flexural strength decreases if more than $0.25 \%$ of fibers are used. This behavior results from unsuitable distribution of fibers. The fracture line has approximately passed through the regions with less fibers density. In other words, using more than $0.25 \%$ of fibers in specimens causes the balling phenomenon, which exterminates the effect of fibers practically.

\section{Microstructures}

Studying the microstructure of cement paste and concrete using Scanning Electron Microscope (SEM) images has revealed a new horizon in concrete technology in recent years. Concrete characteristics including specific gravity and all kinds of chemical reactions and hydration that are created in the initial and final setting processes of concrete have a direct and close relationship with the concrete microscopic structure. Therefore, it is necessary to study the microstructure of concrete in the process of cement hydration and the placement state of concrete besides various admixtures such as the materials added to concrete, including various types of fibers and pozzolans using SEM, which are very important. In this investigation, PPF and nano-silica were added to concrete, and detailed studies of their arrangement in the concrete structure were conducted.

Figure 16(a) illustrates the reference specimens without fibers and nano-silica in which porosity in the concrete structure in these specimens is quite evident. Moreover, Figure 16(b) depicts a specimen with $0.25 \%$ of optimum PPF and $4 \%$ of nano-silica. As can be seen from Figure 16(b), the mechanical properties have been improved using optimum PPF in the presence of nano-silica in the concrete. In addition, nano- 


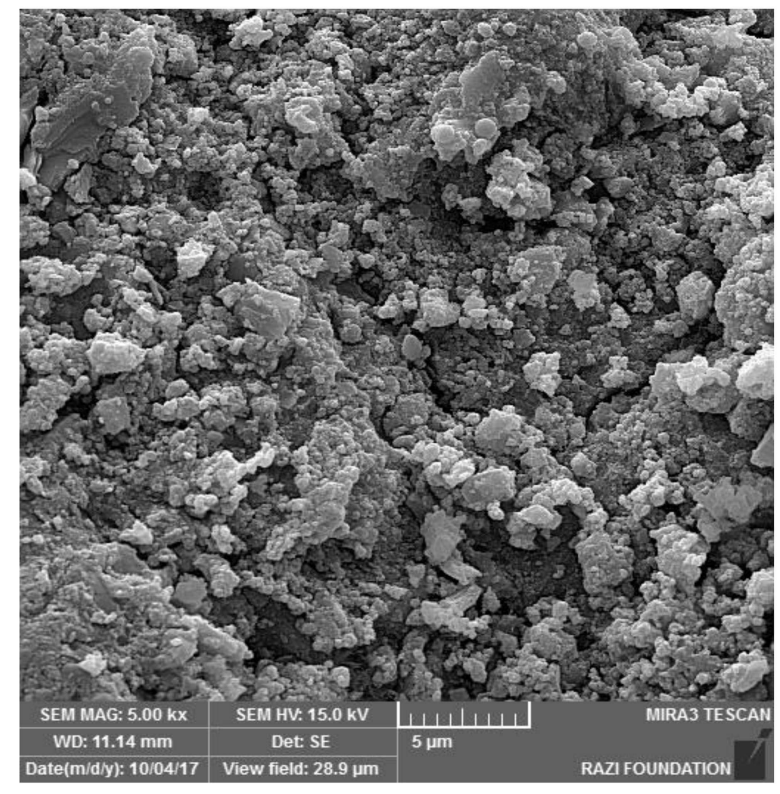

(a)

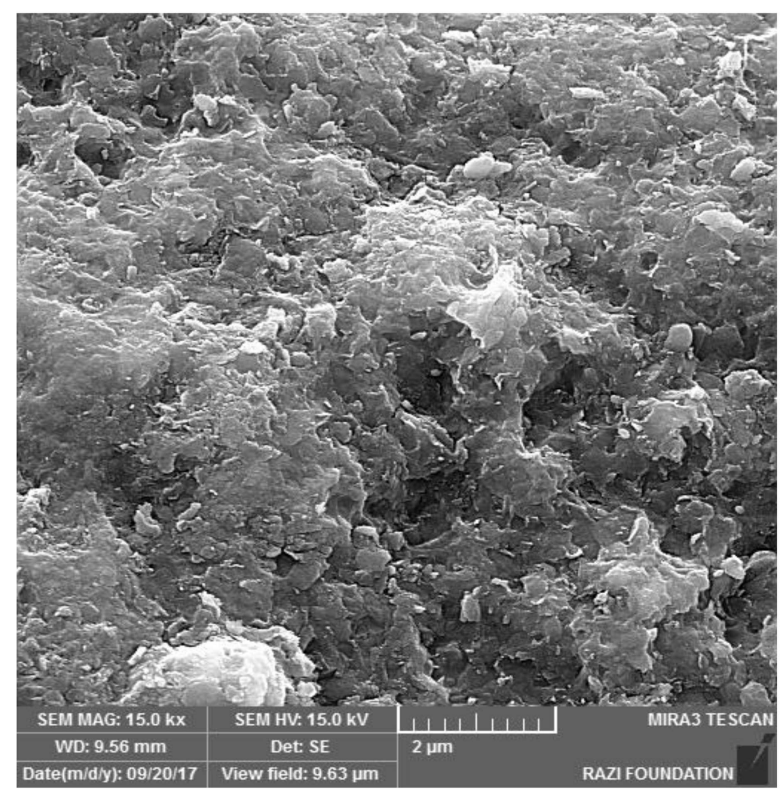

(b)

Figure 16. SEM micrograph: (a) Reference sample (non-fibers and nano-silica), (b) fiber-containing sample ( $0.25 \%$ of polypropylene fibers) and $4 \%$ of nano-silica.

silica to concrete ( $4 \%$ by weight of cement) reduces the volume of cavities and creates a smooth surface with less porosity. The difference between the density of reference sample and the fiber-containing sample is clearly evident.

\section{Conclusion}

Considering the previous investigations and the tests of this research, the following results are obtained:
- Using $0.10 \%$ of fibers and $4 \%$ nano-silica increased the compressive strength at the ages of 7,28 , and 90 days. More than $0.10 \%$ utilization of fibers decreased the compressive strength of specimens at any age due to unsuitable distribution of fibers. The constant value of superplasticizer and increasing the fibers content decreased the slump of concrete and affected the reduction of compressive strength of specimens. The porosity of concrete specimens increased with the addition of fibers;

- The slope of abrasion depth curve dwindled by increasing the water-cement ratio from 0.3 to 0.5 ; this could be associated with the biphasic (mortar and aggregates) nature of concrete in abrasion. The abrasion resistance of mortar phase decreased by increasing the water-cement ratio, and the abrasion resistance of concrete approached the abrasion resistance of aggregates. Therefore, to increase the abrasion resistance of concrete, mortar and aggregates should be reinforced together. Reducing the watercement ratio, nano-silica and polypropylene fibers (PPF) utilization, and timely and proper curing can boost the mortar phase. The aggregate phase will boost by using abrasion-resistant aggregates;

- Using up to $0.15 \%$ of fibers and $4 \%$ nano-silica increased the abrasion resistance of the specimens. The abrasion resistance of the specimens decreased by more than $0.15 \%$ addition of fibers. The porosity increment of specimens due to much more fiber addition and the absence of polymer admixtures, which does not make a suitable cohesion between fibers and concrete matrix, caused this behavior of concrete. Therefore, a suitable cohesion between fibers and concrete either by the apparent form or the polymer material addition to concrete is an appropriate solution for improving the abrasion resistance of concrete;

- The reduction of concrete's permeability in the presence of fibers resulted from the placement of fibers between the connection paths of pores that obstruct them; hence, the capillarity, which is a resonant factor of permeability, would be removed and, therefore, the permeability of specimens would reduce;

- Using up to $0.15 \%$ of fibers and $4 \%$ nano-silica decreased the penetration depth of water and permeability of specimens. These factors will increase if more than $0.15 \%$ of fibers are used. This behavior is due to higher porosity of specimens by more than optimum value addition of fibers;

- Using up to $0.25 \%$ of fibers and $4 \%$ nano-silica increased the tensile and flexural strength of specimens. It is expected that the tensile and flexural strength of specimens will decrease if more than 
$0.25 \%$ of fibers are used. This behavior results from the unsuitable distribution of fibers, which is obvious on the apparent surface of those specimens. The fracture line approximately passed through the regions with less fiber density. In other words, using more than $0.25 \%$ of fibers in specimens caused the balling phenomenon, exterminating the effect of fibers practically;

- In the presence of fibers in the specimens, two main statuses between cracks and fibers were observed: vertical and horizontal. If fibers pass through the edges of cracks vertically, the integrity of concrete will be preserved until large deformations occur due to fibers bridging between cracks and the flexural strength increases due to cracks sewn by fibers;

- It is clear from the Scanning Electron Microscope (SEM) images of the fracture surfaces of hardened paste that the presence of nano- silica and polypropylene fibers at optimum levels improved the density of the cement paste structure, and the paste structure had clearly higher density and uniformity in the presence of these two materials.

\section{References}

1. Pospichal, O., Kucharczykova, B., Misak, P., and Vymazal, T. "Freeze-thaw resistance of concrete with porous aggregate", Proc. Eng., 2(1), pp. 521-529 (2010).

2. Sanchez, F. and Sobolev, K. "Nanotechnology in concrete - a review", Const. Build. Materials, 24(11), pp. 2060-2071 (2010).

3. Sneff, L., Labrincha, J.A., Ferreira, V.M., Hotza, D., and Repette, W.L. "Effect of nano-silica on rheology and fresh properties of cement pastes and mortars", Const. Build. Materials, 23(7), pp. 2487-2491 (2009).

4. Qing, Y.E., Zenan, Z.H., Deyu, K., and Rongshen, C.H. "Influence of nano- $\mathrm{SiO}_{2}$ addition on properties of hardened cement paste as compared with silica fume", Const. Build. Materials, 21, pp. 539-545 (2007).

5. Jeng-ywan, S., Ta-peng, C., and Tien-chin, H. "Effect of nano-silica on characterization of Portland cement composite", Materials Sci. Eng. A, 424, pp. 266-274 (2006).

6. Mostofinejad, D. and Farahbod, F. "Parametric study on moment redistribution in continuous RC beams using ductility capacity concept", Iran. J. Sci. Tech., Trans. B: Eng., 31, pp. 459-471 (2007).

7. Ozawa, M. and Morimoto, H. "Effects of various fibres on high-temperature spalling in high-performance concrete", Constr. Build. Materials, 71, pp. 83-92 (2014).

8. Dehghan, S.M., Najafgholipour, M.A., Kamrava, A.R., and Khajepour, M. "Application of ordinary fiberreinforced concrete layer for in-plane retrofitting of unreinforced masonry walls: Test and modeling", Scientia Iranica, 26, pp. 1089-1103 (2019).
9. Badv, K. and Omidi, A. "Effect of synthetic leachate on the hydraulic conductivity of clayey soil in Urmia city landfill site", Iran. J. Sci. Tech., Trans. B: Eng., 31, pp. 535-545 (2007).

10. ACI Committee 544, State-of-the-Art Report on Fiber Reinforced Concrete, ACI 544.1-96, American Concrete Institute, Farmington Hills, MI (1997).

11. Ma, H.L., Cui, C., Li, X., and Hu, S.L. "Study on mechanical properties of steel fiber reinforced autoclaved lightweight shell-aggregate concrete", J. Mater. Des., 52, pp. 565-571 (2014).

12. Shafigh, P., Mahmud, H., and Jumaat, M.Z. "Effect of steel fiber on the mechanical properties of oil palm shell lightweight concrete", J. Mater. Des, 32, pp. 39263932 (2011).

13. Mirsayar, M., Shi, X., and Zollinger, D. "Evaluation of interfacial bond strength between Portland cement concrete and asphalt concrete layers using bi-material SCB test specimen", Eng. Solid Mech., 5(4), pp. 293306 (2017).

14. Jafari, Kh., Tabatabaeian, M., Joshaghani, A., and Ozbakkaloglu, T. "Optimizing the mixture design of polymer concrete: An experimental investigation", Const. Build. Materials, 167, pp. 185-196 (2018).

15. Shariati, A., Shariati, M., Ramli Sulong, N.H., Suhatril, M., Arabnejad Khanouki, M.M., and Mahoutian, M. "Experimental assessment of angle shear connectors under monotonic and fully reversed cyclic loading in high strength concrete", Const. Build. Materials, 52, pp. 276-283 (2014).

16. Ali, I. "New generation adsorbents for water treatment", Chem. Rev., 112, pp. 5073-5091 (2012).

17. Banthia, N. and Gupta, R. "Influence of polypropylene fiber geometry on plastic shrinkage cracking in concrete", Cem. Concr. Res., 36, pp. 1263-1267 (2006).

18. Shoemaker, C., Quiroga, P., Whitney, D., Jirsa, J., Wheat, H., and Fowler, D. "Detailed evaluation of performance FRP wrapped columns and beams in a corrosive environment", Research Report No. 0-17743, Tex. Dep. Transport. (2004).

19. Won, J., Park, C., Lee, S., Jang, C., and Won, C. "Effect of crimped synthetic fibre surface treatments on plastic shrinkage cracking of cement-based composites", Mag. Concr. Res., 60, pp. 421-428 (2008).

20. Rashiddadash, P., Ramezanianpour, A.A., and Mahdikhani, M. "Experimental investigation on flexural toughness of hybrid fiber reinforced concrete (HFRC) containing metakaolin and pumice", Const. Build. Materials, 51, pp. 313-320 (2014).

21. Brandt, A.M. "Fiber reinforced cement-based (FRC) composites after over 40 years of development in building and civil engineering", Compos. Struct., 86, pp. 3-9 (2008).

22. Farnam, Y., Mohammadi, S., and Shekarchi, M. "Experimental and numerical investigations of low velocity 
impact behaviour of high-performance fiber reinforced cement based composite", Int. J. Impact. Eng., 37(2), pp. 220-229 (2010).

23. Ponikiewski, T. and Katzer, J. "Mechanical characteristics of green SCC modified by steel and polymer fibres", Rocznik Ochrona Środowiska, 16(1), pp. 173185 (2014).

24. Song, P.S. and Hawang, S. "Mechanical properties of high-strength steel fiber reinforced concrete", Const. Build. Materials, 18(9), pp. 669-673 (2004).

25. Lim, J.C. and Ozbakkaloglu, T. "Influence of silica fume on stress-strain behavior of FRP-confined HSC", Const. Build. Materials, 63, pp. 11-24 (2014).

26. Yazici, H. "The effect of curing conditions on compressive strength of ultra-high strength concrete with high volume mineral admixtures", Build. Environ., 42(5), pp. 2083-2089 (2007).

27. Mohammadhassani, M., Suhatril, M., Shariati, M., and Ghanbari, F. "Ductility and strength assessment of HSC beams with varying of tensile reinforcement ratios", Struct. Eng. Mech., 48(6), pp. 833-848 (2013).

28. Yermak, N., Pliya, P., Beaucour, A.-L., Simon, A., and Noumowe, A. "Influence of steel and/or polypropylene fibers on the behavior of concrete at high temperature: Spalling, transfer and mechanical properties", Const. Build. Materials, 132, pp. 240-250 (2017).

29. ASTM C 136, Standard Specification for Standard Sand, Annual Book of ASTM standards (2010).

30. ACI Committee 211, Standard Practice for Selecting Proportions for Normal, Heavyweight and Mass Concrete, American Concrete Institute, USA (2009).

31. BS 1881: Part 116, Testing Concrete: Method for Determination of Compressive Strength of Concrete Cubes, British Standard Institution, London (1983).

32. ASTM C 418, Standard Test Method for Abrasion Resistance of Concrete by Sandblasting (2010).
33. ISO 1920-5, Testing of Concrete-Part 5: Properties of Hardened Concrete other than Strength, Article 5 of this standard specifies the procedure for determination of the depth of penetration of water under pressure (2012).

34. ASTM C 496, Standard Test Method for Splitting Tensile Strength of Cylindrical Concrete Specimens (2010).

35. ASTM C 1018, Standard Test Method for Flexural Toughness and First Crack Strength of Fiber Reinforced Concrete (using beam with third point loading).

\section{Biographies}

Saber Piroti is currently a PhD student of Civil Engineering in Islamic Azad University of Arak. His main interest is in the field of design of concrete structures, structural engineering, and concrete technology.

Mohsen Najarchi is an Assistant Professor at Civil Engineering Department of Islamic Azad University of Arak. He teaches and studies in the field of hydraulic engineering, hydrology, and hydraulic structures.

Emadaldin Hezavehi is an Assistant Professor at Textile Engineering Department of Islamic Azad University of Arak. His main research interest is in the field of using polymeric fibers in concrete reinforcement and improvement.

Mohammad Mahdi Najafizadeh is currently a Professor at Mechanical Engineering Department of Islamic Azad University of Arak. He teaches and studies in the field of applied mechanics.

Seyyed Mohamad Mirhosseini is currently an Assistant Professor of Civil Engineering in Islamic Azad University of Arak. He investigates the design of fiber concrete, dampers, and dynamic study of wind turbines. 